E13-2001-168

V.A.Morozov, N.V.Morozova, Yu.V.Norseev, Zh.Sereeter, V.B.Zlokazov

\title{
HIGH-SENSITIVITY DELAYED-COINCIDENCE SPECTROMETER TO SEARCH FOR SHORT-LIVED NUCLEAR STATES
}

Submitted to «Nuclear Instruments and Methods A» 
Nanosecond and microsecond short-lived nuclear states arising from the radioactive decay are mostly identified by the delayed coincidence method, usually with two detectors recording excitation and de-excitation radiation of an isomeric state. The number of true coincidences is $N_{\text {true }} \sim \omega_{1} * \omega_{2}$, where $\omega_{1}$ and $\omega_{2}$ are the solid angles corresponding to the angles at which detectors record the radiation; therefore, to provide the maximum true coincidence recording efficiency, the solid angle for both detectors should be $\omega=4 \pi$. The simplest way to meet this requirement is to use a single-detector coincidence spectrometer with the radioactive source implanted or placed in the sensitive volume of the detector (scintillating or semiconducting material). The present investigation is further development of the single-crystal scintillation time spectroscopy method intended for searching for isomeric states [1-8]. Since it is required not only to observe an isomeric state and to find its lifetime but also to find its energy and energies of its excitation and de-excitation $\gamma$-transitions, a semiconductor HPGe detector was used together with the $4 \pi$ autocorrelation single-crystal scintillation time spectrometer (ASSTS) in the delayed-coincidence spectrometer. This combination allowed recording of coincidences with $\gamma$-rays populating and de-exciting short-lived states in radioactive nuclei. The activity of the sources studied was comparable with background level in the laboratory room.

A schematic diagram of the autocorrelation E-T coincidence spectrometer is displayed in Fig. 1. The first signal arriving at the discriminator D forms a signal 
triggering the START channel of the time-to-amplitude converter TAC and also passed to the coincidence circuit, and monovibrator. The maximum duration of the analyzed time range is dictated by the monovibrator pulse duration. For this signal one can use, for example, the BUSY output from the time-to-pulse height converter (ORTEC TPHC467). The signal from the coincidence circuit forms a STOP signal supplied to the TAC. The delay line DL is used to eliminate self-coincidences. The energy spectrum of delayed coincidences is formed by a linear integration nanosecond pulse circuit - LIN. The search for isomers in the nanosecond range requires the use of fast scintillators, and photomultipliers, and short-dead-time discriminators. Advantages of the autocorrelation method for recording of delayed coincidence are obvious: it ensures the maximum recording efficiency for populating and delayed radiation, including the entire Compton distribution recorded by the plastic scintillator, because the discriminator threshold can be set only slightly higher than the photomultiplier noise and afterpulse level. The block diagram of a two-detector four-dimensional triple-coincidence time spectrometer is displayed in Fig. 2. The spectrometer of this type comprises a photomultiplier XP2020Q with a NE104 plastic scintillator. The source is included in the plastic scintillator, which ensures $4 \pi$ measurement. Varying the size of the plastic scintillator, one can effectively record $\alpha, \beta, e$,-particles or $\gamma$-radiation. For this type of spectrometer it becomes fundamentally important to obtain an ultimately short photomultiplier output pulse and to use a discriminator with ultimately short dead time for ensuring high efficiency of measurements in the nanosecond range. Since the duration of the output signal from XP2020Q photomultiplier is no longer than $5 \mathrm{~ns}$, the dead time of the discriminator $-t_{d}$ crucially affects the measurement efficiency in the nanosecond range (Fig. 3). This figure is displayed the solid angle coincidence efficiency of the ASSTS and the two detector spectrometer (TDS) assuming that for each detector of the last spectrometer a solid angle is $\omega=2 \pi$. Efficiency of radiation registration is accepted equal $100 \%$. Both the semiconductor and the scintillator detector can be used as a $\gamma$-detector. The ASSTS spectrometer may be also effectively used for a CRYSTAL BALL type spectrometer. The four-dimensional coincidence mode E1-E2-E3-T is realized as a combinations of three-dimensional E1-E2-T coincidences at the ASSTS and coincidences of $\gamma$-rays with 
them, E3, in the $\gamma$-detector channel. E2 and E1 are the radiations populating and deexciting the isomeric state that are recorded by sandwich scintillator of the ASSTS, E3 are the cascade rays related to E1 or E2 transitions and recorded by the semiconductor or scintillation $\gamma$-detector, and $\mathrm{T}$ is the time distribution spectrum. Unlike the case in ordinary fast-slow delayed coincidence circuits, no fast discriminator is used in the $\gamma$ spectrometer channel and the pulse height signal from the $\gamma$-detector goes through the spectrometric amplifier (SA) to the ADC opened by the control signal SCA from the TAC if the ASSTS recorded an isomeric state. The advantage of this approach is a $100 \%$ coincidence recording efficiency in the low-energy region of the $\gamma$ spectrum. The spectrometer comprises the following electronic modules: a fast amplifier ORTECFFA-579, a constant fraction discriminator (CFD) ORTEC-CFD-584, a time-to-pulse height converter ORTEC-TPHC-467, and a linear integration nanosecond pulse circuits - LIN1 and LIN2 [9]. LIN1 transmits the E1 signal characterizing the delayed radiation energy recorded by the plastic scintillator and LIN2 transmits the E2 signal characterizing the excitation radiation energy recorded by the same plastic scintillator. The data acquisition system is described in [8]. Isomers identified with this spectrometer fell within a time range from $4 \mathrm{~ns}$ to $4 \mu \mathrm{s}$.

This spectrometer was used to redefine the half-life of the ${ }^{213} \mathrm{Po}$ nucleus produced by a long radioactive chain decay beginning with ${ }^{229} \mathrm{Th}$ (Fig. 4). A $10 \mathrm{~mm}$ diameter by $6 \mathrm{~mm}$ height plastic scintillator was used in the measurements. It provided $4 \pi$ geometry for recording radiation in the ${ }^{229} \mathrm{Th}$ chain. $\mathrm{A}{ }^{225} \mathrm{Ac}$ source separated from the equilibrium ${ }^{229} \mathrm{Th}$ source was also used in some experiments. The observed time distribution with $T_{1 / 2}=3.70 \mu$ s allowed it to be assigned to the ${ }^{213}$ Po ground state decay, see Fig. 5. This figure also illustrates measurements of half-lives of other short-lived states with the ASSTS. Figure 6 displays radioactive ${ }^{225}$ Ac chain radiation spectra received at scintilation detector with a plastic scintillator: a single spectrum (curve 1) and a delayed coincidence spectrum (curve 2), which is an $\alpha$-spectrum arising from the ${ }^{213} \mathrm{Po}$ decay. The ${ }^{229} \mathrm{Th}$ source was used for investigation of the ${ }^{213} \mathrm{Bi} \gamma$-spectrum during the recording of $(\alpha-\beta-\gamma)$ coincidences. We used the scintillation detector with the $40 \mathrm{~mm}$ 
diameter by $50 \mathrm{~mm}$ height $\mathrm{NaI}(\mathrm{Tl})$ crystal and the semiconductor HPGe detector with a $10 \%$ efficiency. The experiment with the scintillation detector was 6 hours long - Fig. 7. The ASSTS counting rate was at a level of $\sim 10001 / \mathrm{s}$, the counting rate for the single $\gamma$ spectrum recorded by scintillation spectrometer was $\sim 1001 / \mathrm{s}$. The experiment with the HPGe detector and $\mathrm{a}^{229} \mathrm{Th}$ source was 22 hours long. The ASSTS counting rate was 1300 1/s, the HPGe detector counting rate (source + background) was $\sim 170$ 1/s (80 1/s $+901 / \mathrm{s})$. The semiconductor detector was used without any shielding. The background radiation contribution can be estimated from Fig. 8 .

The $\alpha-\beta-\gamma$ coincidence spectrum features distinct $\gamma$-lines belonging to the ${ }^{213} \mathrm{Bi}$ $\rightarrow{ }^{213} \mathrm{Po}$ decay, which corresponds to the ${ }^{213} \mathrm{Bi}$ decay scheme [10] (Fig. 6 and 9). These lines are distinct against a very sophisticated $\gamma$-spectrum from the decay of 12 nuclei $\left({ }^{229} \mathrm{Th}\right.$ chain) and from the background radiation with the major admixtures from the radioactive ${ }^{232} \mathrm{Th}$ chain nuclei and ${ }^{226} \mathrm{Ra},{ }^{137} \mathrm{Cs},{ }^{60} \mathrm{Co}$, and ${ }^{40} \mathrm{~K}$ nuclei. Accidental coincidences in the chosen measurement time range $\Delta \mathrm{T}=3.2 \mu$ s can be ignored because low count rate of the source, which is also evident from comparison of intensity of the $807.4\left({ }^{213} \mathrm{Bi}\right)$ with intensities of $1764.5\left({ }^{226} \mathrm{Ra}\right)$, and $2614.5-\left({ }^{208} \mathrm{Tl}\right) \mathrm{keV}$ lines in the single spectrum and in coincidence spectrum. Table 1 presents the experimental data characterizing $\gamma$-ray intensities belonging to the $\beta$-decay of ${ }^{213} \mathrm{Bi}$ in accordance with well known data. S - number of counts, $\varepsilon$ - a recording efficiency coefficient of HPGe detector. Distortion of the true coincidence spectrum could only arise from recording of coincidences initiated by afterpulses at a rather low threshold of the CFD in the ASSTS [13]. However, for each type of photomultiplier there is quite accurately time reference of afterpulses to its main pulse and thus the contribution from afterpulses to the coincidence $\gamma$-spectrum can be taken into account during time sorting of events. Xradiation in the coincidence spectrum will be recorded only if $\gamma$-transitions exciting or de-exciting the short-lived state in the $\alpha$ and $\beta$ - decay or the electron-capture have noticeable conversion coefficients. The very fact of recording X-radiation in the coincidence $\gamma$-spectrum allows one to find $\mathrm{Z}$ of the nucleus with the short-lived state in question. We stress again that the coincidence efficiency in the $\mathrm{KX}$-spectrum is as large 
as $100 \%$. Thus, a possibility of identifying short-lived nuclear states in a complex mixture of radioactive isotopes at a source activity comparable with the natural background is demonstrated. By way of example Fig. 10 displays the ultimately short half-life of the $103-\mathrm{keV}$ state in ${ }^{153} \mathrm{Eu}$ measured by this method. Figures 11 and 12 display the measured half-life of the $13.2-\mathrm{keV}$ state in ${ }^{73} \mathrm{Ge}$ and the radiation energy spectra obtained with the ASSTS in this experiment.

Actually, based on the ASSTS and the semiconductor detector, a method of labelled nuclei featuring an isomeric or a short-live ground state is developed since the coincidence spectra reveal the entire system of cascade $\gamma$-transitions exciting or deexciting these states and registration of the $\mathrm{X}$-radiation makes it possible to find $\mathrm{Z}$ of the nucleus where these transitions are observed. Spectrometers of this type are mainly intended for being used in on-line experiments with charged or neutral particle beams and in analysis of radioactive decay of nuclei. The high sensitivity of the spectrometers makes it possible to investigate radioactive decay of nuclei that arise from nuclear reactions with small cross sections and whose activity is at the level of the natural background. The efficiency of the search for nanosecond and microsecond isomers is illustrated with the ${ }^{213} \mathrm{Bi}$ decay in a long radioactive chain beginning with ${ }^{229} \mathrm{Th}$ and including successive decay of 12 radioactive isotopes and decay a number of isotopes belonging to the background activity. An undeniable advantage of the method is the $100 \%$ coincidence recording efficiency in the low-energy region of the spectrum at a high true-to-accidental coincidence ratio.

The authors are grateful to V.B.Brudanin and V.G.Kalinnikov for their continuous support, and to M.I.Potapov for his assistance. 
Table 1.

\section{Gamma-Rays at ${ }^{213} \mathrm{Bi}$ Decay}

\begin{tabular}{|c|c|c|c|c|c|}
\hline $\mathrm{E} \gamma, \mathrm{keV}$ & $\begin{array}{c}\mathrm{I} \gamma(\%) * \\
{[11]}\end{array}$ & $\begin{array}{c}\mathrm{I} \gamma(\%) \\
{[14]}\end{array}$ & $\mathrm{S}(\Delta \mathrm{S})$ & $\mathrm{S} / \varepsilon \times 10^{3}$ & $\begin{array}{c}\mathrm{I} \gamma(\%) \\
\text { Present data }\end{array}$ \\
\hline 292.76 & $0.42(2)$ & $0.39(2)$ & $655(64)$ & $81(8)$ & $0.31(4)$ \\
\hline 440.43 & $26.1(3)^{* *}$ & $24.6(15)$ & $35070(195)$ & $6810(38)$ & $26.1(2)$ \\
\hline 659.77 & $0.036(2)$ & $0.044(3)$ & $30(12)$ & $9(3)$ & $0.035(11)$ \\
\hline 710.81 & $0.010(1)$ & $0.0119(10)$ & $12(7)$ & $4(2)$ & $0.015(8)$ \\
\hline 807.38 & $0.241(15)$ & $0.283(18)$ & $185(16)$ & $70(6)$ & $0.27(2)$ \\
\hline 867.98 & $0.011(1)$ & $0.0123(11)$ & $15(8)$ & $6(4)$ & $0.023(13)$ \\
\hline 1003.55 & $0.050(5)$ & $0.053(3)$ & $23(6)$ & $11(3)$ & $0.04(1)$ \\
\hline 1100.02 & $0.259(16)$ & $0.251(17)$ & $115(11)$ & $59(6)$ & $0.23(2)$ \\
\hline 1119.29 & $0.050(3)$ & $0.051(3)$ & $20(5)$ & $11(3)$ & $0.04(1)$ \\
\hline
\end{tabular}

* For 100 total decay $(\alpha+\beta)$ of the parent.

** Normalization value from Ref. [12].

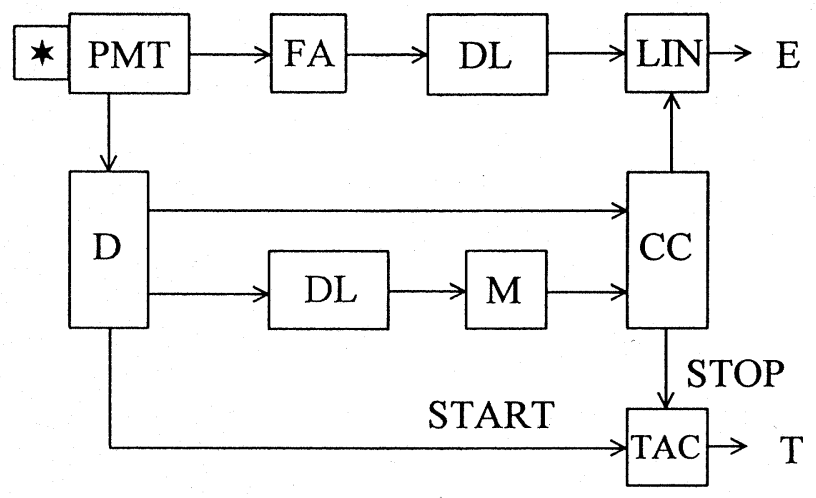

Fig. 1.

Block diagram of the autocorrelation single-crystal scintillation two-dimensional coincidence time spectrometer. FA-fast amplifier, DL-delay line, LIN-linear integration nanosecond pulse circuit, D-discriminator, M-monovibrator, $\mathrm{CC}$ coincidence circuit, TAC-time-to-pulse height converter 


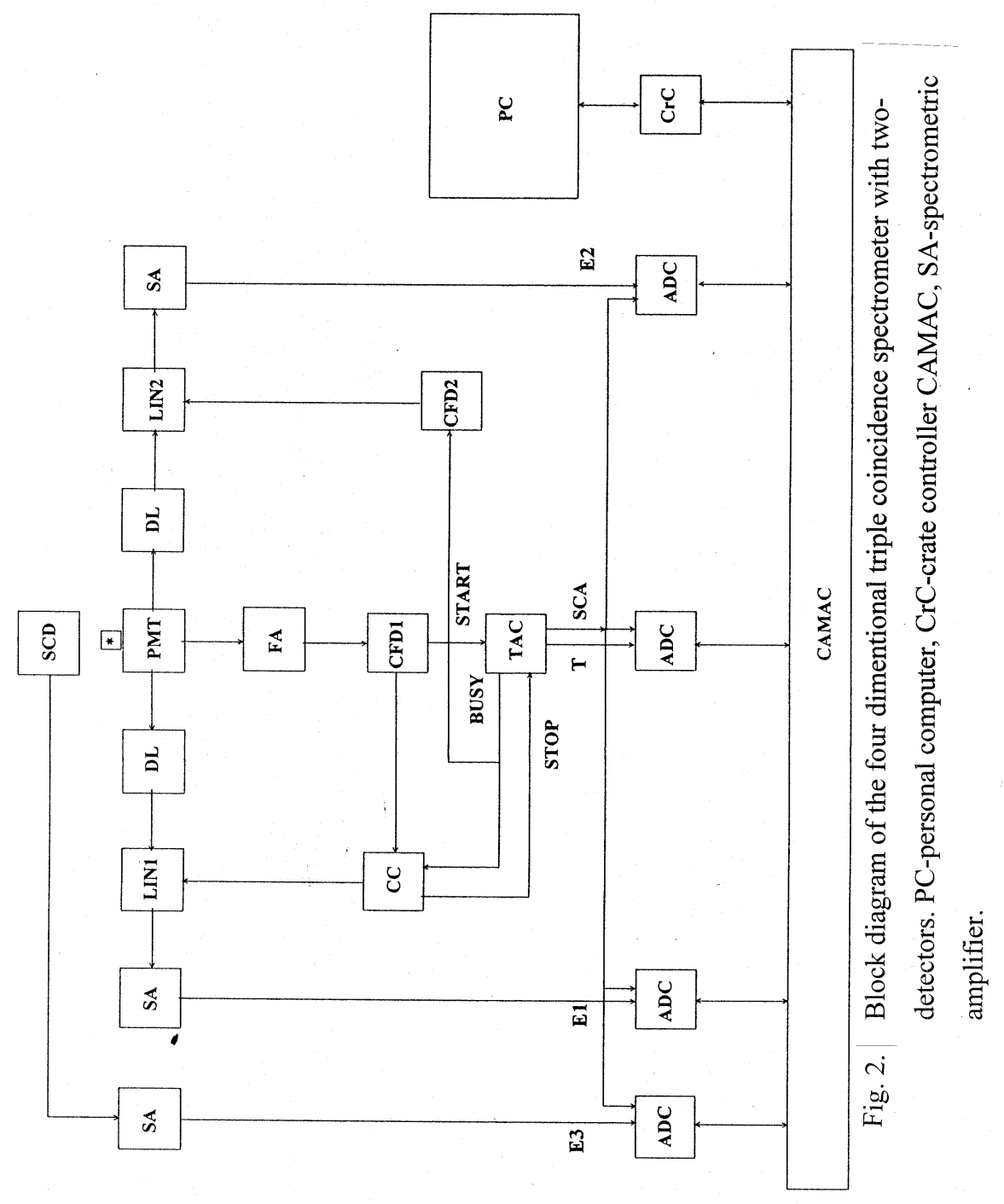




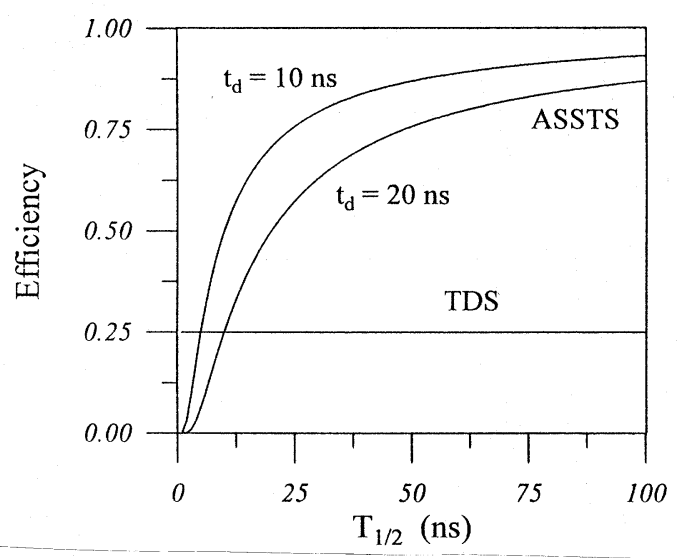

Fig. 3.

Delayed coincidence recording efficiency of the two-detector spectrometer (TDS) and the autocorrelation scintillation single-crystal time spectrometer (ASSTS).

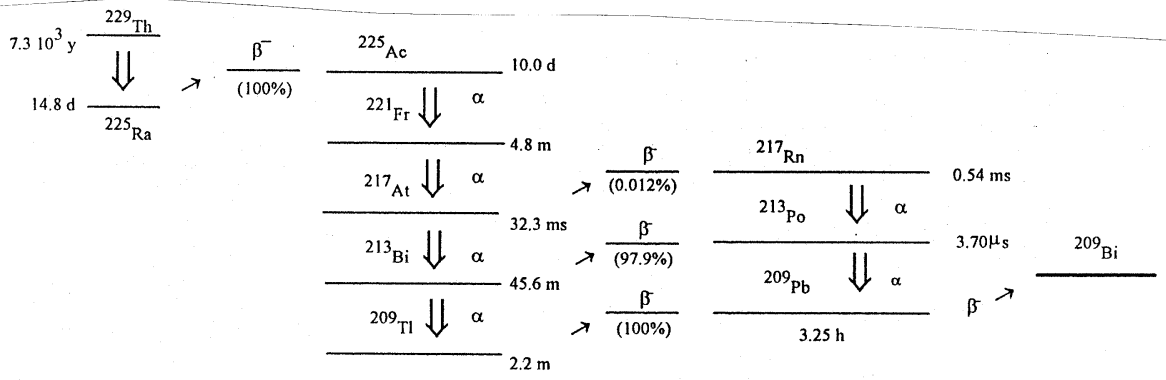$$
9 / 2 \frac{213_{\mathrm{Bi}}}{\alpha \downarrow_{2.1 \%} \searrow^{\beta}} 97.6 \mathrm{~m}
$$

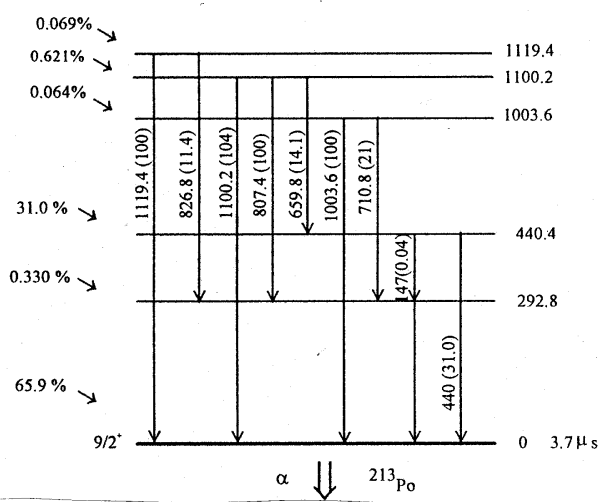

Fig. 4. Radioactive ${ }^{229} \mathrm{Th}$ chain and the ${ }^{213} \mathrm{Bi}$ decay scheme 


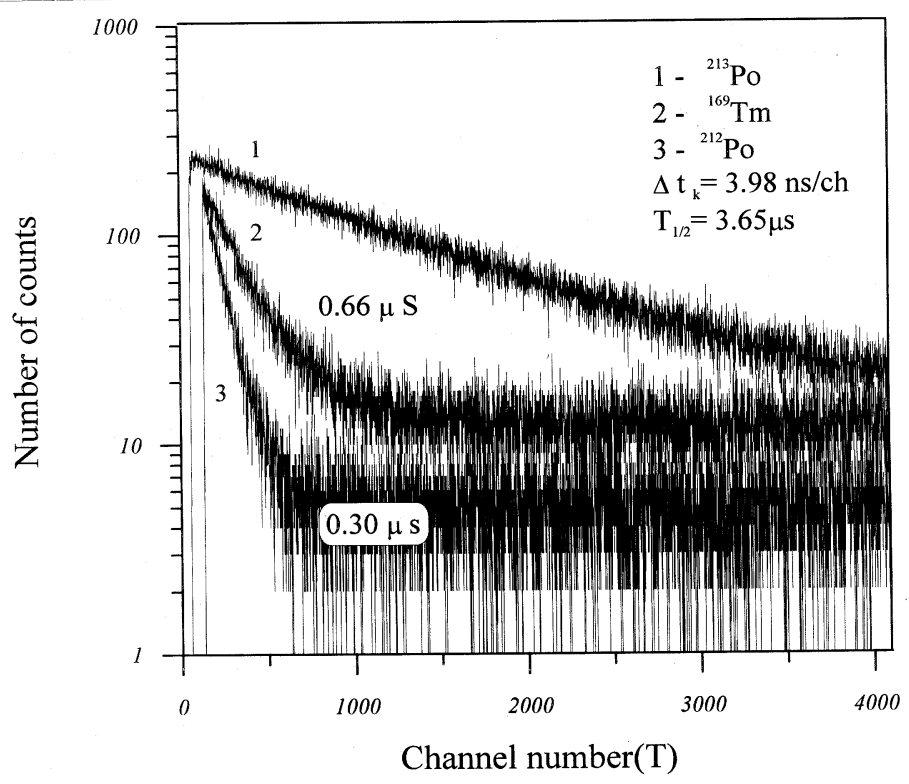

Fig. 5.

Half-lives of the ground and isomeric states in radioactive nuclei

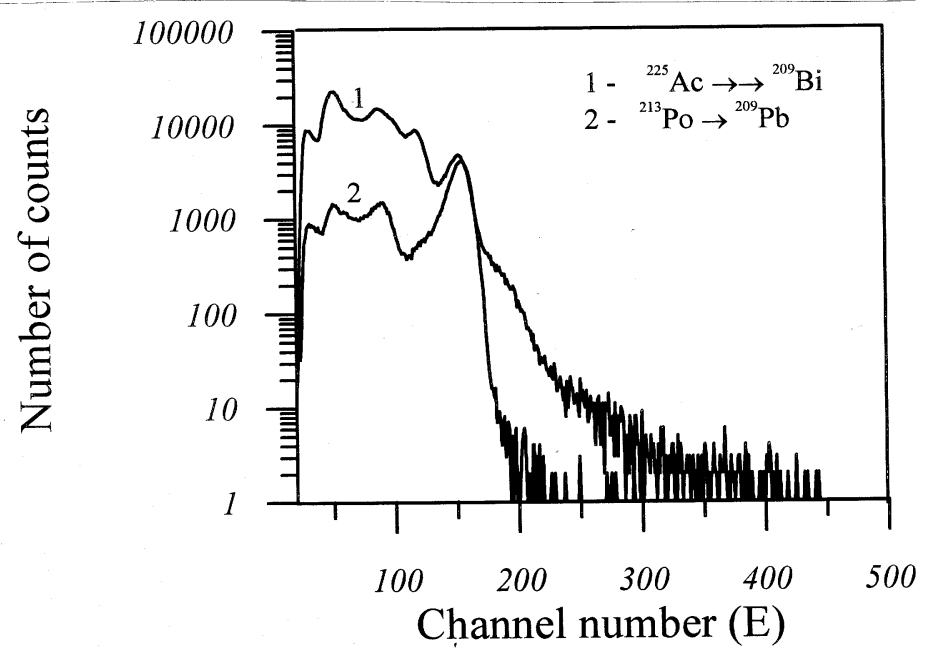

Fig. 6.(1) Radiation spectrum of the radioactive ${ }^{225}$ Ac chain. (2) ${ }^{213}$ Po decay $\alpha$-spectrum 


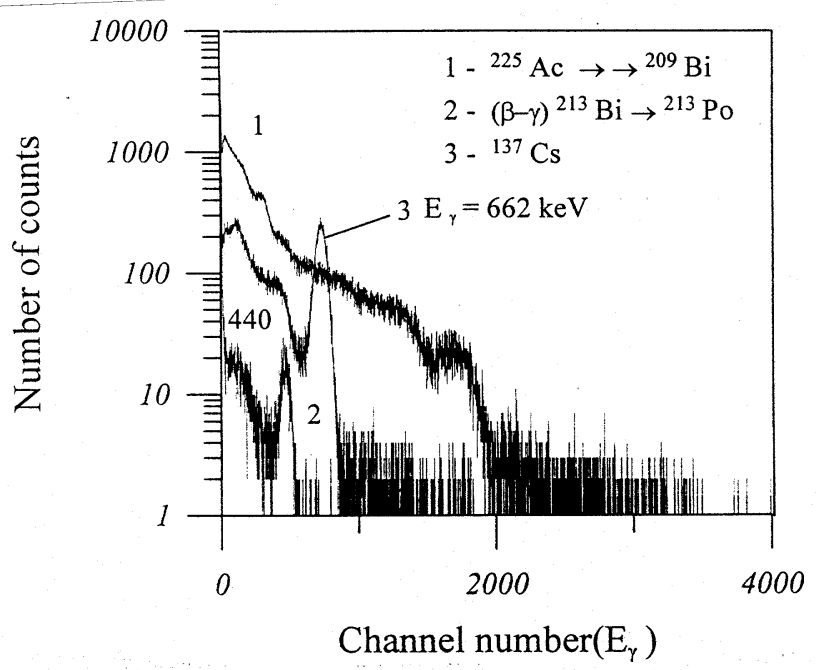

Fig. 7.

(1) Gamma spectrum of the radioactive ${ }^{225}$ Ac chain. (2) Gamma spectrum of triple ( $\alpha$ $\beta$ - $\gamma$ ) coincidences at the ${ }^{213} \mathrm{Bi}$ decay. (3) Calibration ${ }^{137} \mathrm{Cs} \gamma$-spectrum

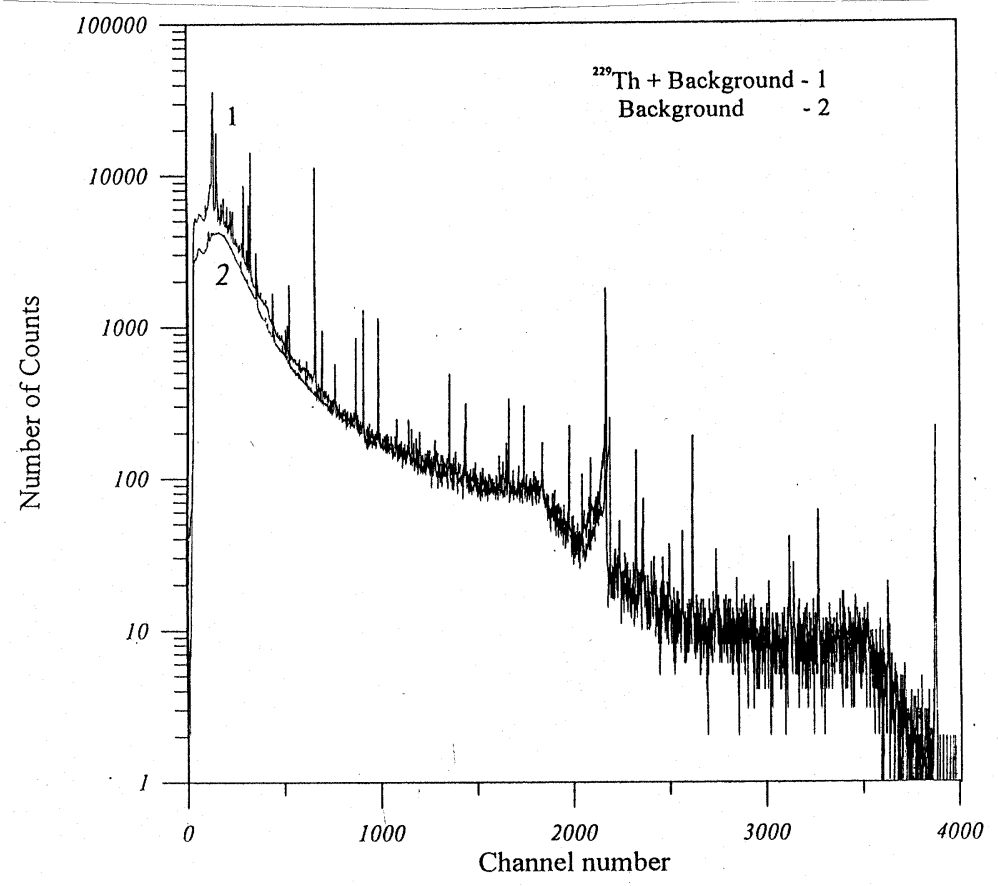

Fig. 8. Gamma spectrum of the ${ }^{229} \mathrm{Th}$ chain and the background radiation 


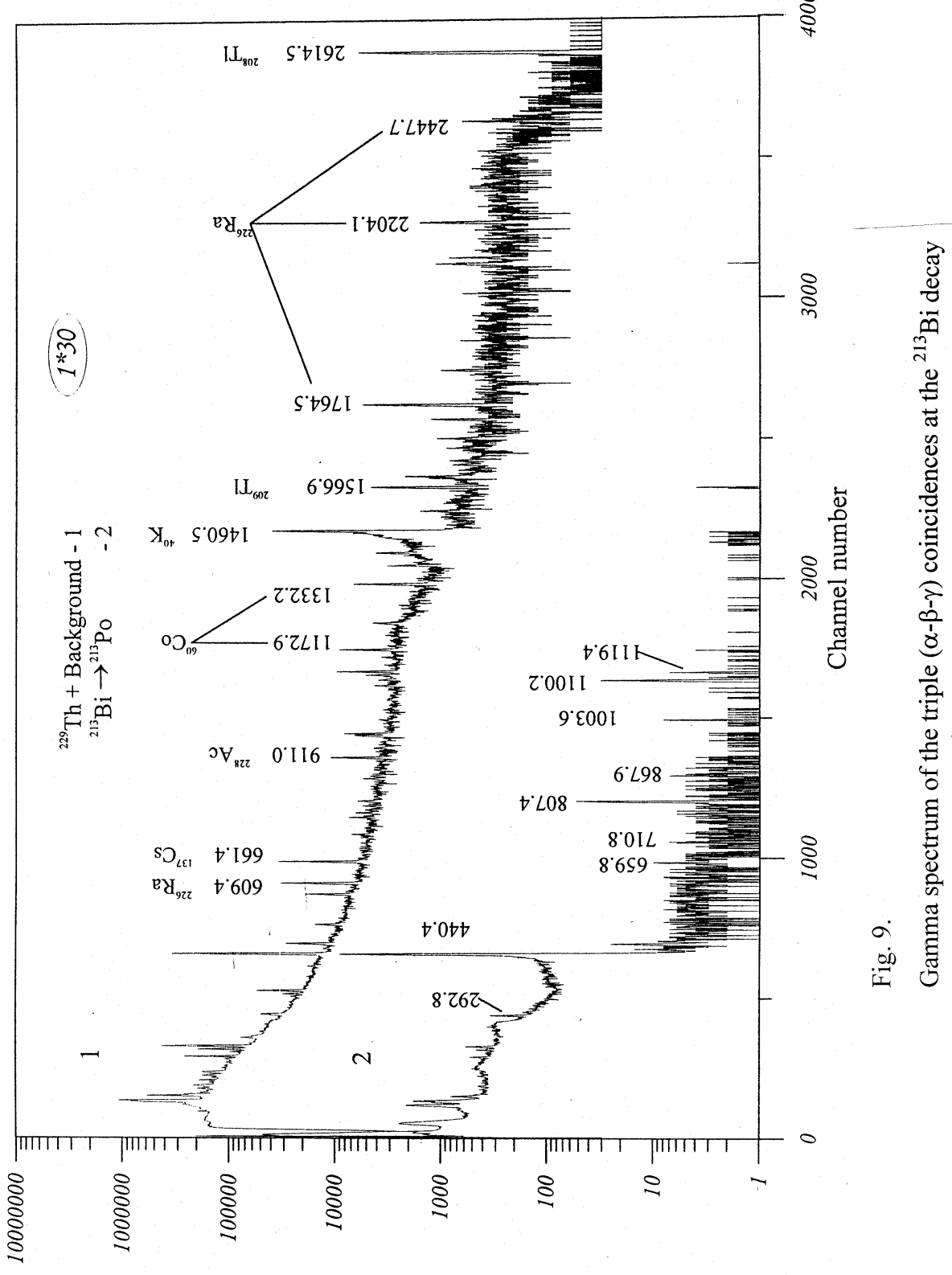

słunoว Jo JəquinN 


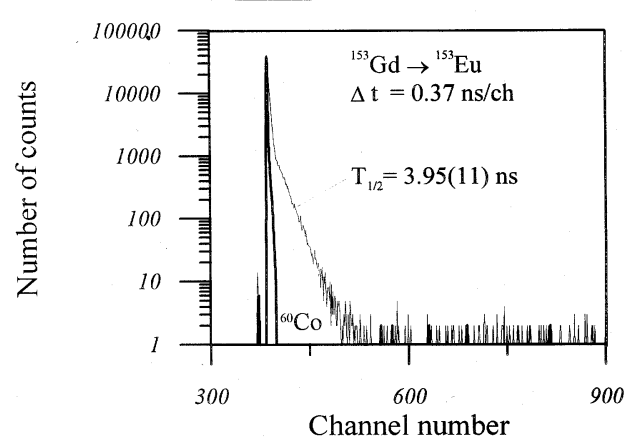

Fig. 10.

Half-life of the $103-\mathrm{keV}$ state in ${ }^{153} \mathrm{Eu}$

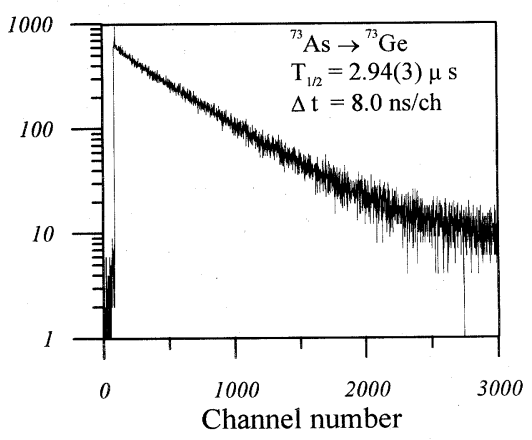

Fig. 11.

Half-life of the 13.2 -keV state in ${ }^{73} \mathrm{Ge}$

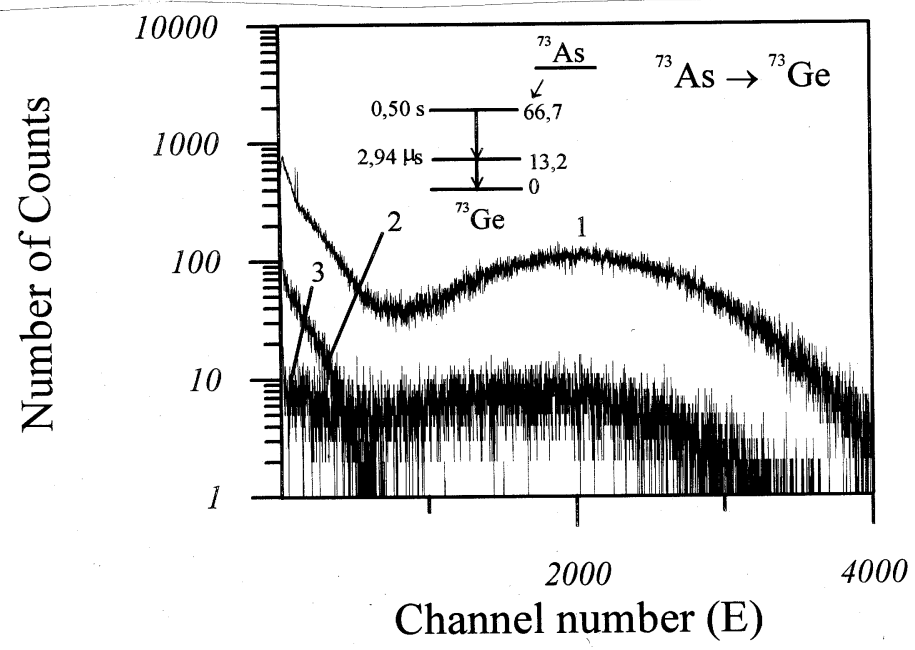

Fig. 12.

Energy spectra at the ${ }^{73} \mathrm{Ac}$ decay: (1) the single spectrum, (2) the delayed radiation spectrum, (3) the spectrum of the radiation exciting the isomeric state 


\section{References}

1. P.A.Tove, Nucl.Instr. and Meth. V.1. (1957) 95.

2. J.Radeloff, N.Buttler, W.Kesternich et all., Nucl.Instr.and Meth. V.47. (1967)109.

3. J.Glatz, K.E.G.Lobner, Nucl.Instr.and Meth. V.94. (1971)237.

4. V.A.Morozov, T.M.Muminov, Prib. Tekh. Eksp.,№1. (1973)79.

5. M.Budzinski, V.S.Butsev, V.A.Morozov, Yad. Fiz., V.21. (1975)913.

6. V.A.Morozov, N.V.Morozova, N.A.Lebedev, Preprint JINR., Dubna, 10-87-928. (1987).

7. V.A.Morozov, I.N.Churin, N.V.Morozova, Prib. Tekh. Eksp., №5.(1998)21.

8. V.A.Morozov, V.G.Kalinnikov, N.V.Morozova et all., Prib. Tekh. Eksp., №5. (1998)26.

9. U.G.Budyashov, V.G.Zinov, B.S.Krasnoborodov., Prib. Tekh. Eksp., №1. (1972)114.

10. R.B.Firestone, Table of Isotopes, VII. John Wiley \& Sons,INC, (1996).

11. G.Ardisson, V.Barci, O.El Samal, Phys. Rev C V.57. №2. 612-620 (1998).

12. R.G.Helmer, C.W.Reich, M.A.Lee, G.Ardisson., Int.J.Appl. Radiat.Isot. 37. (1986)139.

13. V.A.Morozov, N.V.Morozova., Prib. Tekh. Eksp., .№4. (1997)97.

14. K.Ya.Gromov, S.A.Kudrya, Sh.P.Malikov et all., Preprint JINR., Dubna. P6-2000101. (1987). 
Морозов В.А. и др.

Высокочувствительный спектрометр задержанных совпадений для поиска короткоживущих ядерных состояний

Создан высокочувствительный четырехмерный спектрометр тройных совпадений на основе автокорреляционного однокристального сцинтилляционного временного $4 \pi$-спектрометра и полупроводникового HPGe-детектора. Спектрометр задержанных совпадений предназначен для поиска изомерных нано- и микросекундных состояний в короткоживущих ядрах и $\gamma$-лучей, связанных с ними. Проведены измерения периодов полураспада короткоживущих состояний в диапазоне от 4 нс до 4 мкс. Уровень активности моноизотопного источника, достаточный для проведения исследований, не превышает 0,01 мкКи.

Работа выполнена в Лаборатории ядерных проблем им. В.П.Джелепова ОИЯИ.

Препринт Объединенного института ядерных исследований. Дубна, 2001

Morozov V.A. et al.

E13-2001-168

High-Sensitivity Delayed-Coincidence Spectrometer to Search

for Short-Lived Nuclear States

A high-sensitivity four-dimensional triple-coincidence spectrometer with two detectors is developed on the basis of an autocorrelation single-crystal scintillation time $4 \pi$ spectrometer and a semiconductor HPGe detector. The delayed-coincidence spectrometer is designed for searching for isomeric nano- and microsecond states in short-lived nuclei and for their related $\gamma$-rays. Half-lives of short-lived states are measured in the range from $4 \mathrm{~ns}$ to $4 \mu \mathrm{s}$. The sufficient activity of the monoisotopic source for the investigations does not exceed $0.01 \mu \mathrm{Ci}$.

The investigation has been performed at the Dzhelepov Laboratory of Nuclear Problems, JINR. 
Макет Н.А.Киселевой

Подписано в печать 27.08.2001

Формат $60 \times 90 / 16$. Офсетная печать. Уч.-изд. л. 1,01

Тираж 315. Заказ 52833. Цена 1 р. 1 к.

Издательский отдел Объединенного института ядерных исследований Дубна Московской области 